\title{
An Effective Method for Inversion of Elastic Impedance for Shallow Sediments and Its Application to Gas Hydrate-Bearing Sediments
}

Scientific Investigations Report 2006-5297 


\section{An Effective Method for Inversion of Elastic Impedance for Shallow Sediments and Its Application to Gas Hydrate-Bearing Sediments}

By Myung W. Lee

Scientific Investigations Report 2006-5297 


\title{
U.S. Department of the Interior DIRK KEMPTHORNE, Secretary
}

\author{
U.S. Geological Survey \\ Mark D. Myers, Director
}

\section{U.S. Geological Survey, Reston, Virginia: 2006}

Posted online January 2007

This publication is available only online at http://pubs.usgs.gov/sir/2006/5297/

For more information on the USGS--the Federal source for science about the Earth, its natural and living resources, natural hazards, and the environment:

World Wide Web: http://www.usgs.gov

Telephone: 1-888-ASK-USGS

Any use of trade, product, or firm names is for descriptive purposes only and does not imply endorsement by the U.S. Government.

Although this report is in the public domain, permission must be secured from the individual copyright owners to reproduce any copyrighted materials contained within this report.

Suggested citation:

Lee, M.W., 2006, An effective method for inversion of elastic impedance for shallow sediments and its application to gas hydrate-bearing sediments: U.S. Geological Survey Scientific Investigations Report 2006-5297, 11 p. 


\section{Contents}

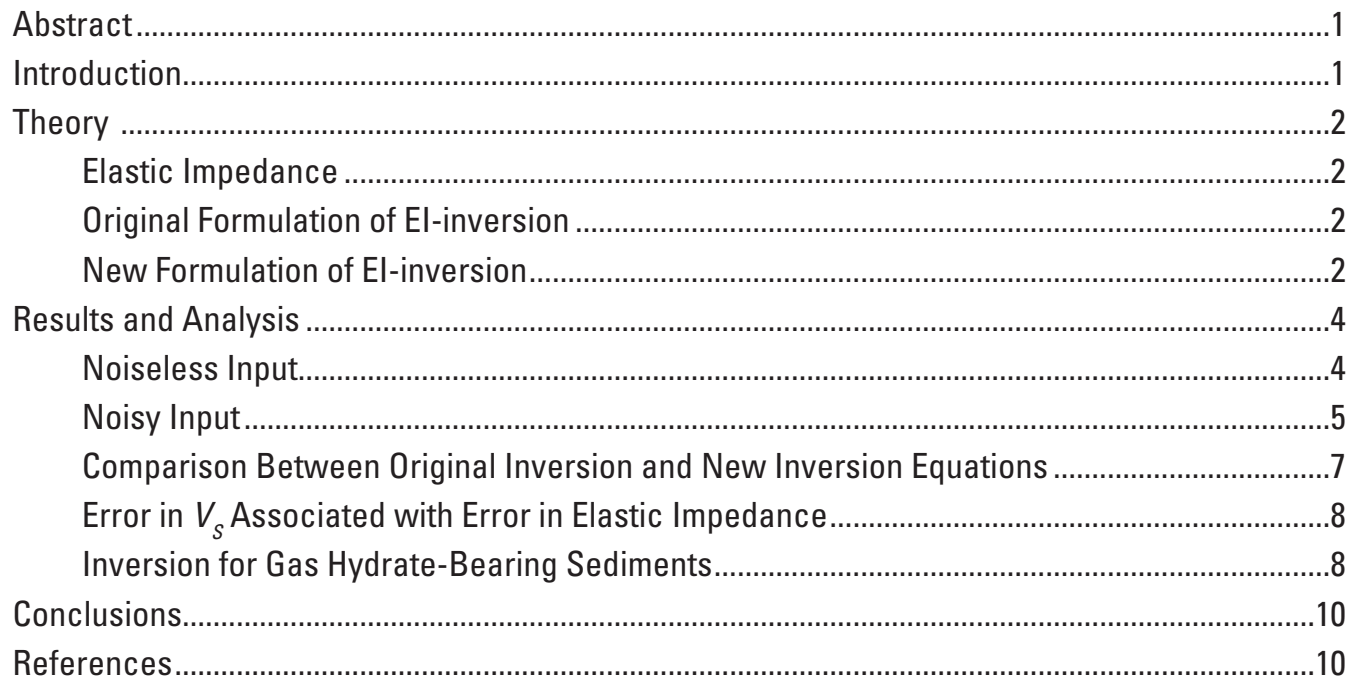

\section{Figures}

1-9. Graphs showing:

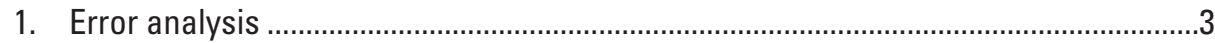

2. Inversion results from the new formula using noiseless elastic impedance..............4

3. Inversion results using noisy elastic impedance at the Keathley Canyon

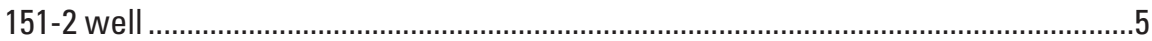

4. Inversion results using noisy elastic impedance at the Alpine-1 well .......................6

5. Inversion results from the new formula using noisy elastic impedance .....................6

6. The $S$-wave velocity simulated at the Keathley-Canyon 151-2 well ..........................7

7. Gain factor with respect to the fractional error in elastic impedance .......................8

8. Inversion results for gas hydrate-bearing sediments at the Keathley Canyon 151-2 well

9. Inversion results for gas hydrate-bearing sediments at the Mallik $5 L-38$ well, Canada 


\title{
An Effective Method for Inversion of Elastic Impedance for Shallow Sediments and Its Application to Gas Hydrate-Bearing Sediments
}

\author{
By Myung W. Lee
}

\begin{abstract}
Elastic properties of gas hydrate-bearing sediments (GHBS) are important for identifying and quantifying gas hydrate as well as discriminating the effects of free gas on velocity from that due to overpressure. Elastic properties of GHBS sediments can be estimated from elastic inversion using the elastic impedance. The accuracy of elastic inversion can be increased by using the predicted S-wave velocity $\left(V_{S}\right)$ in the parameter $k$, which is $k=\left(V_{S} / V_{P}\right)^{2}$. However, when $V_{S}$ is less than about 0.6 kilometer per second, the inversion is inaccurate, partly because of the difficulty in accurately predicting low S-wave velocities and partly because of the large error associated with small $k$ values. A new formula that leads to estimates of only the high-frequency part of velocity is proposed by decomposing $V_{S}$ into low- and high-frequency parts. This new inversion formula is applied to a variety of well logs, and the results demonstrate its effectiveness for all ranges of $V_{S}$ as long as the deviation of $V_{S}$ from the low-frequency part of $V_{S}$ is small. For GHBS, the deviation of $V_{S}$ from the lowfrequency part of $V_{S}$ can be large for moderate to high gas hydrate saturations. Therefore, the new formula is not effective for elastic inversion for GHBS unless the gas hydrate effect is incorporated into the low-frequency part of $V_{S}$. For inversion of GHBS with $V_{S}$ greater than about 0.6 kilometer per second, the original formulation is preferable.
\end{abstract}

\section{Introduction}

Identification and quantification of gas hydrate present in sediments are important research areas (Collett, 2002), and detailed seismic analysis is necessary to detect gas hydratebearing sediments (GHBS). Gas hydrate increases the seismic velocities of sediments; therefore, the effect manifests itself in the amplitude and traveltime of seismic data. By comparing seismically driven interval velocities to those for sediments without gas hydrate, GHBS can be identified and quantified (for example, see Tinivella and Lodolo, 2000; Lu and McMechan, 2002; Jin and others, 2003).
Detailed velocity information for sediments is essential to accurately estimate the amount of gas hydrate. Arrival times provide the low-frequency velocity information, and amplitudes provide the high-frequency information of velocities. By combining the amplitude and traveltime information, detailed interval velocities can be estimated. The high-frequency part of velocity information can be deduced from the amplitude-versus-offset (AVO) intercept and gradient or elastic impedances calculated through angle stacks.

Elastic impedance (EI) is a generalization of acoustic impedance (AI) using a three-term approximation of reflection coefficients (Connolly, 1999). AI has been used successfully to derive P-wave velocities for GHBS (Sakai, 1999; Lu and McMechan, 2002; Jin and others, 2003). However, more detailed seismic-attribute analysis for GHBS can be accomplished by estimating S-wave velocities from the seismic data using elastic inversion (Mallick and others, 2000; Lu and McMechan, 2002).

Elastic inversion can be calculated in different ways-for example, by full prestack inversion (Mallick, 1999), by poststack inversion using AVO (AVO-inversion), and by poststack inversion using elastic impedance (EI-inversion). Although computationally expensive, the full prestack inversion is optimum for obtaining elastic parameters from seismic data. Many good results are obtained, however, by using AVOinversion (Mallick, 2001) or EI-inversion (Lu and McMechan, 2004).

Detailed inversion methods using the elastic impedances are discussed in Lee (2006), where predicted S-wave velocities are used to increase the accuracy of inversion without assuming $V_{S} / V_{P}=0.5$ or some constant (Connolly, 1999; Mallick and others, 2000; Mallick, 2001). The inversion proposed by Lee (2006) is problematic, however, when $V_{S}$ is less than about 0.6 kilometer per second $(\mathrm{km} / \mathrm{s})$, which is the velocity range for most GHBS in marine environments.

In this paper, a new effective formula for elastic inversion for low $\mathrm{S}$-wave velocities (less than about $0.6 \mathrm{~km} / \mathrm{s}$ ) is proposed by decomposing $V_{S}$ into low- and high-frequency parts. The new formula is applied to well logs acquired at the Keathley Canyon 151-2 well, Gulf of Mexico; Alpine-1 well, 
North Slope of Alaska; and Mallik 5L-38, western Canada, with promising results. By using the new formula for $V_{S}$ less than about $0.6 \mathrm{~km} / \mathrm{s}$ and the original formula for $V_{s}$ greater than about $0.6 \mathrm{~km} / \mathrm{s}$, accurate $\mathrm{S}$-wave velocities for GHBS can be estimated at the Mallik 5L-38 well.

\section{Theory}

\section{Elastic Impedance}

Impedance is generally defined as a product of P-wave velocity, and density and is related to a normal-incidence reflection seismogram. However, this definition cannot be applied to far-offset data. In order to generalize the normal incidence impedance concept, Connolly (1999) defined EI as follows:

$$
E I(\theta)=V_{p}^{\left(1+\tan ^{2} \theta\right)} V_{s}^{-8 k \sin ^{2} \theta} \rho^{\left(1-4 k \sin ^{2} \theta\right)}
$$

with the parameter $k=\left(V_{S} / V_{P}\right)^{2} . V_{P}, V_{s}, \rho$, and $\theta$, are $\mathrm{P}$-wave velocity, $\mathrm{S}$-wave velocity, density, and angle of incidence, respectively. The dimension of EI in equation 1 varies with respect to the angle of incidence. In order to avoid this dimension change in EI, a normalized elastic impedance concept is used in this report (Whitcombe, 2002).

\section{Original Formulation of El-inversion}

A detailed description of EI-inversion is given in Lee (2006). A practical way of EI-inversion is using a sequential inversion of AI and EI (Lu and McMechan, 2004; Lee, 2006). $\mathrm{P}$-wave impedance is estimated from the $\mathrm{AI}$-inversion using $\mathrm{EI}(0)$, and the shear wave-velocity is estimated from the following equation using $\operatorname{EI}(\theta)$,

$$
\ln \left(V_{s}\right)=\frac{\left(1+\tan ^{2} \theta\right) \ln \left(V_{p}\right)-\ln (E I(\theta))+\left(1-4 k \sin ^{2} \theta\right) \ln (\rho)}{8 k \sin ^{2} \theta} .
$$

EI-inversion using equation (2) requires a good estimate of $k$, and it is particularly important to estimate reliable $\mathrm{S}$-wave velocities at shallow depths, where small $k$ values are required.

The error associated with error in $k$ can be derived by writing equation 2 as

$$
\ln \left(V_{s}+\Delta V_{s}\right)=\frac{Q-4 k \sin ^{2} \theta \ln \rho-4 \Delta k \sin ^{2} \theta \ln \rho}{8(k+\Delta k) \sin ^{2} \theta}
$$

where $Q=\left(1+\tan ^{2} \theta\right) 1 \mathrm{n} V_{p}-1 \mathrm{n} E I(\theta)+\ln \rho$. When $k>\Delta k$, equation 3 becomes

$$
\ln V_{s}\left(1+\Delta V_{s} / V_{s}\right)=\ln V_{s}+\ln (1+\varepsilon) \approx\left(\ln V_{s}-\frac{\Delta k \ln \rho}{2 k}\right)\left(1-\frac{\Delta k}{k}\right) .
$$

Therefore,

$$
\begin{gathered}
\ln (1+\varepsilon) \approx-\left(\ln V_{s}+\frac{\ln \rho}{2}\right) \frac{\Delta k}{k} \\
\varepsilon=e^{-\left(\ln V_{s}+\ln \rho / 2\right) \Delta k / k}-1 \approx-\left(\frac{\ln \rho}{2}+\ln V_{s}\right) \frac{\Delta k}{k}
\end{gathered}
$$

When $\Delta k>>k$, the error can be written as

$$
\ln (1+\varepsilon)=\frac{k}{\Delta k}\left(1-\frac{k}{\Delta k}\right) \ln V_{s}-\ln V_{s}-\frac{\ln \rho}{2}\left(1-\frac{k}{\Delta k}\right)
$$

The error of S-wave velocity associated with error in $k$ in the case that an error in $k$ is much larger than $k$ itself is given by

$$
\varepsilon=e^{-\left(\ln V_{s}+\ln \rho / 2\right)}-1
$$

Errors calculated from equations 5 and 7 are shown in figure $1 A$. When the error in $k$ is small, the errors in the estimated $\mathrm{S}$-wave velocities are also small. However, when the error in $k$ is larger than $k$ itself, figure $1 A$ indicates a large error in the predicted S-wave velocity. Note that when $\Delta k>>k$, the error is independent of $k$ and dependent only on the S-wave velocity and density of the medium. This kind of error occurs when S-wave velocities at shallow depths are estimated using EI-inversion. For example, the P- and S-wave velocities at $100-\mathrm{m}$ subbottom depth are typically $1.55 \mathrm{~km} / \mathrm{s}$ and $0.15 \mathrm{~km} / \mathrm{s}$, respectively. This gives a value of $k$ of about 0.1 . If $k$ of 0.21 is used for the inversion, the error in $k$ is about 0.2 , which is 20 times larger than the true $k$. Assuming a density of $1.66 \mathrm{~g} / \mathrm{cm}^{3}$, the error from equation 7 , or approximately from figure $1 A$, is about 4, yielding the estimated $V_{S}=0.15 \mathrm{~km} / \mathrm{s} \times 4 .=0.6 \mathrm{~km} / \mathrm{s}$. Therefore, inverting low $\mathrm{S}$-wave velocities from the seismic data is not practical using equation 2 because the required accuracy of $k$ may not be obtained.

Although $k$ values can be closely estimated, the inversion is inaccurate when $k$ is very small (less than $\sim 0.07$ ). Because $k$ is in the denominator in equation 2, a small error in the input can be accentuated in the inversion results. Therefore, equation 2 is not a practical approach when using EI-inversion with low $\mathrm{S}$-wave velocities.

\section{New Formulation of El-inversion}

As mentioned previously, the inversion scheme shown in equation 2 is sensitive to $k$. Lee (2006) suggested using a more accurate $k$ by using predicted S-wave velocity in the inversion scheme, and this approach works well when $k$ is greater than about 0.1 and noise is small. However, modeling indicates that this approach substantially overestimates $\mathrm{S}$-wave velocity when $k$ is very small, less than about 0.07 as in unconsolidated sediments at shallow depths. Consequently, this approach is inadequate for the elastic inversion for gas hydrate-bearing sediments at shallow depths. 

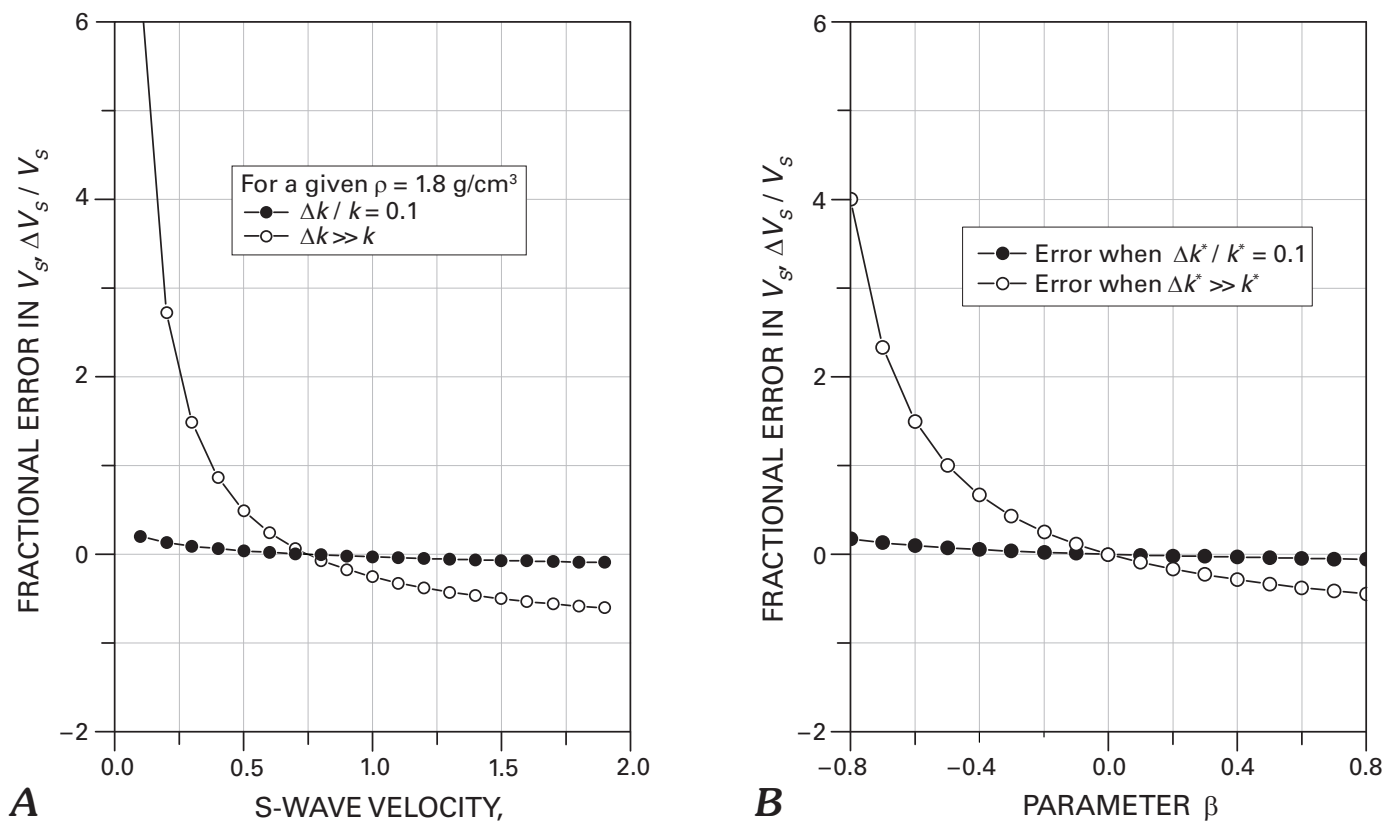

IN KILOMETERS PER SECOND

Figure 1. Error analysis. $A$, Fractional error in $V_{s}$ with respect to $V_{s}$ for a given uncertainty in $k$ when using the original equation, equation 2. $B$, Fractional error in $V_{s}$ with respect to parameter $\beta\left(\beta=V_{s}{ }^{H} / V_{s}{ }^{L}\right)$ for a given uncertainty in $k^{*}$ when using the new equation, equation 11 .

Elastic impedances consist of two components; one is a slowly varying or low-frequency component (sometimes viewed as a trend) and the other is a high-frequency component. The primary function of the low-frequency component is the kinematics of the wave field, which controls arrival times of P- and S-waves. The high-frequency components control the amplitudes of waves. Therefore, it is useful to decompose the EI into two components, and equation 1 can be written, by taking the natural logarithm and assuming that density has only a low-frequency component, as

$$
\begin{aligned}
\ln E I & =\ln E I^{L}(\theta)+\ln (1+\delta)=\left(1+\tan ^{2} \theta\right)\left[\ln V_{P}^{L}+\ln (1+\alpha)\right] \\
& -8 k \sin ^{2} \theta\left[\ln V_{s}^{L}+\ln (1+\beta)\right]+\left(1-4 k \sin ^{2} \theta\right) \ln (\rho)
\end{aligned}
$$

where $\alpha=V_{P}{ }^{H} / V_{p}^{L}, \beta=V_{S}^{H} / V_{S}^{L}, \delta=E I^{H} / E I^{L}$, the superscript $\mathrm{L}$ is the low-frequency component, and the superscript $\mathrm{H}$ is the high-frequency component. The low-frequency component of EI due to the low-frequency part of $V_{S}$ can be written as

$$
\begin{aligned}
\ln E I^{L}(\theta) & =\left(1+\tan ^{2} \theta\right)\left[\ln V_{P}\right]-8 k_{L} \sin ^{2} \theta\left[\ln \left(V_{S}^{L}\right)\right] \\
& +\left(1-4 k_{L} \sin ^{2} \theta\right) \ln (\rho)
\end{aligned}
$$

with $k_{L}=\left(V_{S}^{L} / V_{P}\right)^{2}$.

By subtracting the low-frequency component of elastic impedance from equation 8 using equation 9 , it is shown that equation 8 becomes

$$
\begin{aligned}
& \ln (1+\beta)= \\
& \frac{-\ln (1+\delta)-8\left(k-k_{L}\right) \sin ^{2} \theta \ln \left(V_{S}^{L}\right)-4\left(k-k_{L}\right) \sin ^{2} \theta \ln (\rho)}{8 k \sin ^{2} \theta}
\end{aligned}
$$

The inversion method proposed here is based on the assumption that equation 10 can be approximated by the following equation:

$$
\ln (1+\beta) \approx \frac{\left(1+\tan ^{2} \theta\right) \ln (1+\alpha)-\ln (1+\delta)}{8 k^{*} \sin ^{2} \theta}
$$

The purpose of this formulation is to mitigate the error associated with small values of $k$ in equation 2. If a large $k^{*}$ for small $V_{S}$ can be used in equation 11 and the approximation of equation 11 is valid, errors associated with small $k$ values in the original formula can be reduced.

The parameter $k^{*}$ in equation 11 is different from the parameter $k$ in equations 2 or 10 . The $k^{*}$ is just a convenient parameter, and its value is chosen to yield accurate $\mathrm{S}$-wave velocities from the inversion. Note that values for lowfrequency components are much higher than those for highfrequency components in consolidated sediments. Therefore, in most seismic applications, $\alpha, \beta$, and $\delta$ are small numbers. However, $\beta$ can be large because $V_{S}$ is small at shallow depths. Therefore, a more accurate $V_{S}{ }^{L}$ is required for the inversion of sediments at shallow depth to reduce the magnitude of $\beta$, as shown in the next section.

The error of S-wave velocity associated with the uncertainty in $k^{*}$ using equation 11 when $k^{*}>\Delta k^{*}$ can be written as

$$
\frac{\Delta V_{S}^{H}}{V_{S}}=e^{-(\ln (1+\beta)) \Delta k^{*} / k^{*}}-1 \approx-\ln (1+\beta) \frac{\Delta k^{*}}{k^{*}} .
$$


When $k^{*}<<\Delta k^{*}$, the error becomes

$$
\frac{\Delta V_{S}^{H}}{V_{S}}=e^{-\ln (1+\beta)}-1 .
$$

Figure $1 B$ shows calculated errors for $\Delta k^{*} / k^{*}=0.1$ and $\Delta k^{*} \gg k^{*}$ with respect to the parameter $\beta$. The error increases as the magnitude of $\beta$ increases, which is similar to the behaviors shown in figure $1 A$. However, the magnitude of error is small if the magnitude of $\beta$ is small. In other words, if the lowfrequency part of the $\mathrm{S}$-wave velocity is determined accurately, equation 11 yields more accurate $S$-wave velocities than those estimated from equation 2. Therefore, equation 11 can be used to estimate low S-wave velocities using EI-inversion if reasonable values of $k^{*}$, preferably greater than 0.01 , can be obtained.

\section{Results and Analysis}

\section{Noiseless Input}

Figure 2 shows the estimated S-wave velocities using noiseless EI (0) and EI (25) at the Keathley Canyon 151-2 well, Gulf of Mexico, and the Alpine-1 well, North Slope of Alaska. At the Keathley Canyon 151-2 well, there were no

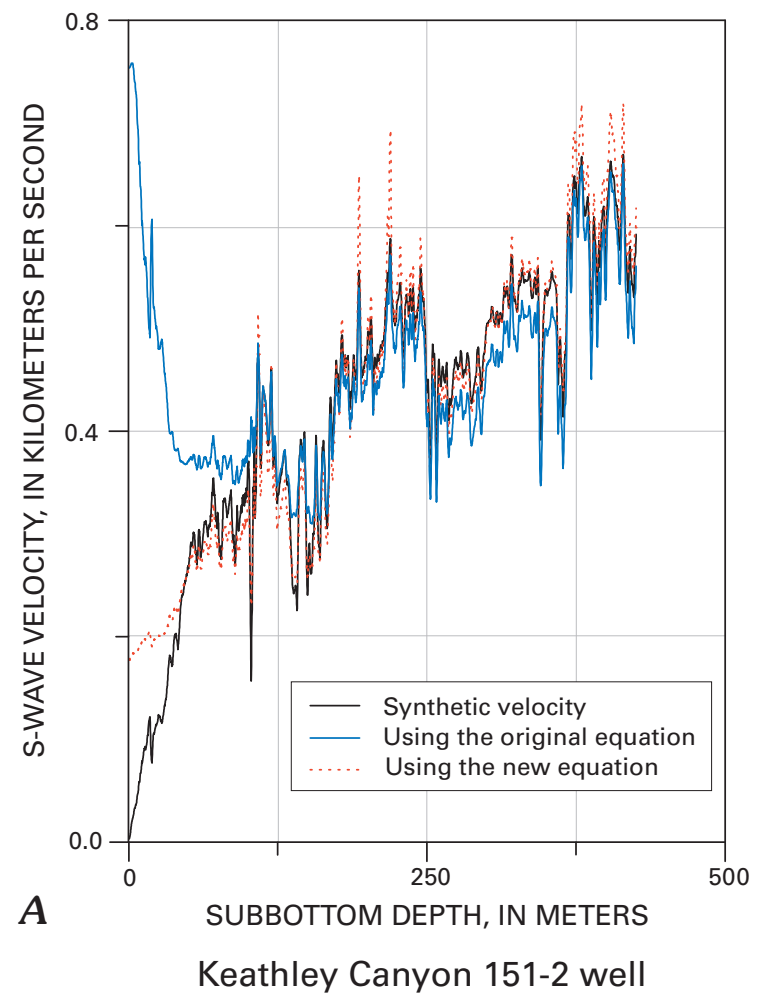

measured velocities, so velocities were predicted from porosities using the modified Biot-Gassmann theory by Lee (Lee, 2002), referred to as the BGTL, with the BGTL parameter $m=1.5$. The calculated velocities are denoted as synthetic velocities in this paper.

In order to estimate a reasonable $k^{*}$ for equation 11 , a series of inversions using different values of $k^{*}$ was performed and $k^{*}$ was chosen based on the accuracy of estimated S-wave velocities. This exercise resulted in the following values of $k^{*}: k^{*}=0.1$ when $V_{S}^{L}<0.2 \mathrm{~km} / \mathrm{s}, k^{*}=0.15$ when $V_{S}^{L}<0.4 \mathrm{~km} / \mathrm{s}$, $k^{*}=1.0$ when $V_{S}^{L}>1.5 \mathrm{~km} / \mathrm{s}$, and $k^{*}$ is linearly interpolated between 0.15 and 1.0 when $0.4<V_{S}{ }^{L}<1.5 \mathrm{~km} / \mathrm{s}$. The red dotted lines in figure 2 show $\mathrm{S}$-wave velocities estimated from equation 11 with these $k^{*}$ values. As indicated, the inverted $\mathrm{S}$-wave velocities using equation 11 are similar to input $\mathrm{S}$-wave velocities for $V_{S}$ greater than about $0.25 \mathrm{~km} / \mathrm{s}$. Note that all inversion results, unless stated, were smoothed using 11 points.

$\mathrm{S}$-wave velocities less than about $0.25 \mathrm{~km} / \mathrm{s}$, shown in figure $2 A$, are not accurate. The smallest $k^{*}$ used in the inversion is 0.1 . In order to estimate very small $\mathrm{S}$-wave velocities accurately, $k^{*}$ should be much smaller than 0.1 . Small values of $k^{*}$, however, yield large errors in S-wave velocities. As will be discussed, the error can be reduced by using the more accurate low-frequency part of $V_{S}$. The advantage of the new formula is its ability to reduce errors by using the more accurate

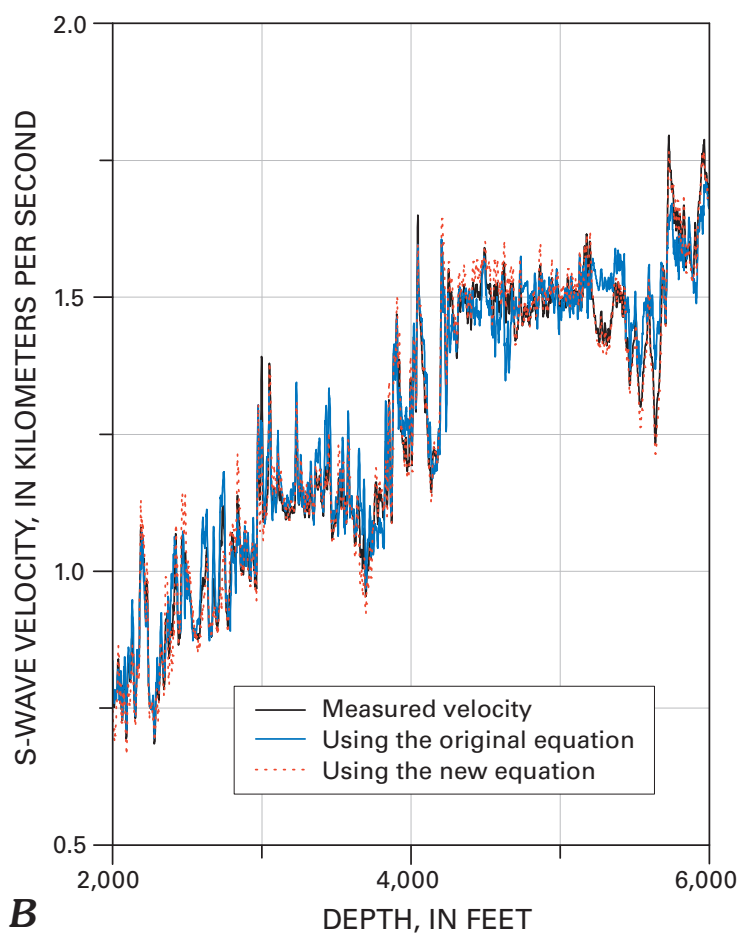

Alpine-1 well

Figure 2. Inversion results from the new formula using noiseless elastic impedance calculated at an incidence angle of $25^{\circ}$. A, At the Keathley Canyon 151-2 well, Gulf of Mexico. The synthetic velocity is the predicted S-wave velocity from porosity. $B$, At the Aline-1 well, North Slope of Alaska. 
low-frequency part of S-wave velocity without decreasing the $k^{*}$ value for small values of $V_{S}$. The original formula is independent of the low-frequency part of the S-wave velocity.

For comparison, the inversion results using the original equation 2 is shown as blue lines in figure 2. For S-wave velocities less than about $0.6 \mathrm{~km} / \mathrm{s}$, the inversion results using the original equation are inferior to those from the new equation, whereas the results are similar for S-wave velocities greater than about $0.6 \mathrm{~km} / \mathrm{s}$.

The accurate inversion results using equation 2 for $V_{S}>0.6 \mathrm{~km} / \mathrm{s}$ are due to accurate $k$ values in the inversion, which are possible because the predicted S-wave velocities were used in calculating $k$, as demonstrated in Lee (2006). The inaccuracy of inversion results using equation 2 for $V_{S}<0.6 \mathrm{~km} / \mathrm{s}$ is due to the inability of obtaining accurate $S$-wave velocities suitable for the calculation of $k$ as well as a small $k$ value.

The accuracy of inversion using equation 2 can be increased with accurate $k$ values, whereas the accuracy of inversion using equation 11 is obtained with an accurate lowfrequency part of S-wave velocity or with a smaller $\beta$. In applying equation 11 , much simpler $k^{*}$ values were estimated and applied instead of using the predicted S-wave velocity. The smallest value of $k^{*}$ used for equation 11 is 0.15 . Therefore, the inverted $\mathrm{S}$-wave velocities using equation 11 at shallow depths are more stable than those estimated from equation 2 , as demonstrated in figure $2 A$.

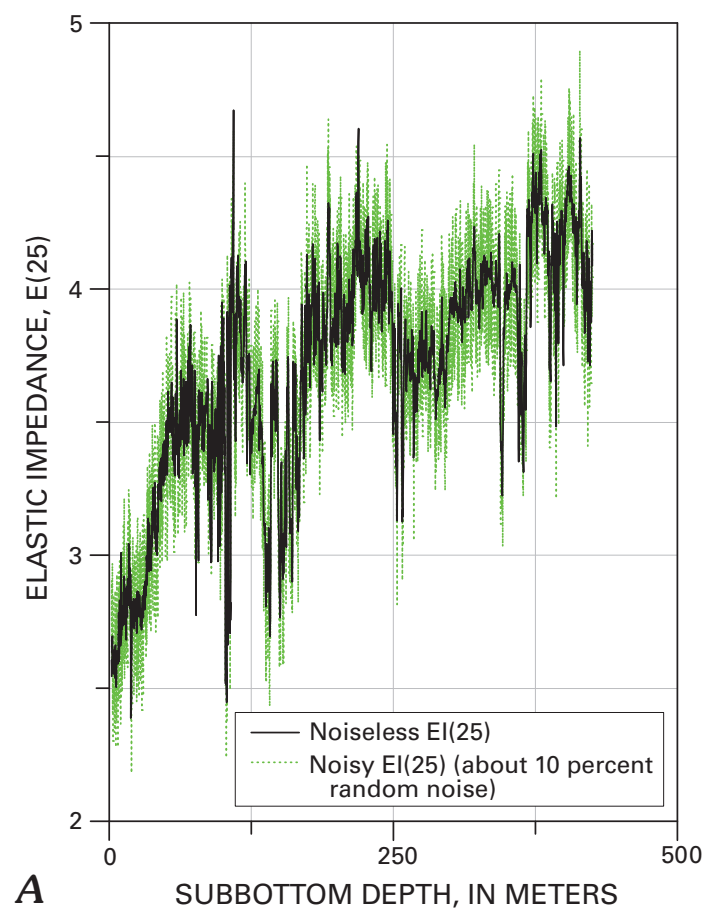

\section{Noisy Input}

Figure $3 A$ shows the noiseless EI(25) and noisy EI(25) at the $\mathrm{KC} 151-2$ well. The noisy $\mathrm{EI}(25)$ is generated by adding 10 percent random noises to the noiseless EI(25). Figure $3 B$ shows the inversion results using equations 2 and 11 . The $\mathrm{S}$-wave velocities estimated using equation 2 are much larger than the input velocities when S-wave velocities are less than about $0.4 \mathrm{~km} / \mathrm{s}$. Also, local variations of $\mathrm{S}$-wave velocities estimated from equation 2 are much larger than those of the input data. However, the estimated $\mathrm{S}$-wave velocities using equation 11 are similar to the input data and are close to the result of noiseless input.

Another example is given in figure 4 for the Alpine-1 well. In this case, the random noise is about 20 percent. The estimated S-wave velocities using equations 2 and 11 are similar and close to measured velocities at the well. The random noise effect on the EI-inversion using the original equation is not much affected when the S-wave velocities are greater than $0.7 \mathrm{~km} / \mathrm{s}$.

For the case where the error in EI is not random noise, the inversion results are shown in figure 5 . The dotted line in figure $5 A$ shows the inverted $S$-wave velocity at the $\mathrm{KC} 151-2$ well using equation 11 when $\Delta E I / E I=0.1$, and figure $5 B$ shows the inverted $S$-wave velocity at the Alpine-1 well when $\Delta E I / E I=0.5$. Figure 5 indicates that the inverted $S$-wave velocities using equation 11 are shifted more toward lower velocities than measured S-wave velocities. However, the local

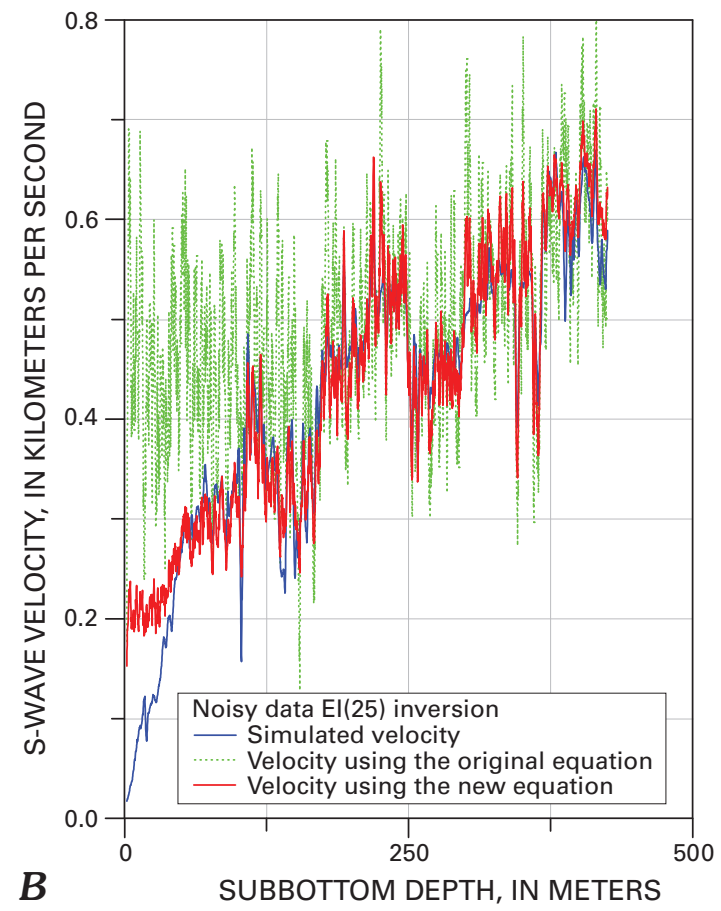

Keathley Canyon 151-2 well

Figure 3. Inversion results using noisy elastic impedance (El) calculated at an incidence angle of $25^{\circ}$ at the Keathley Canyon 151-2 well. A, Noiseless EI(25) with a black line and noisy EI(25) with green line. B, Inversion results using the original and new formulas. 

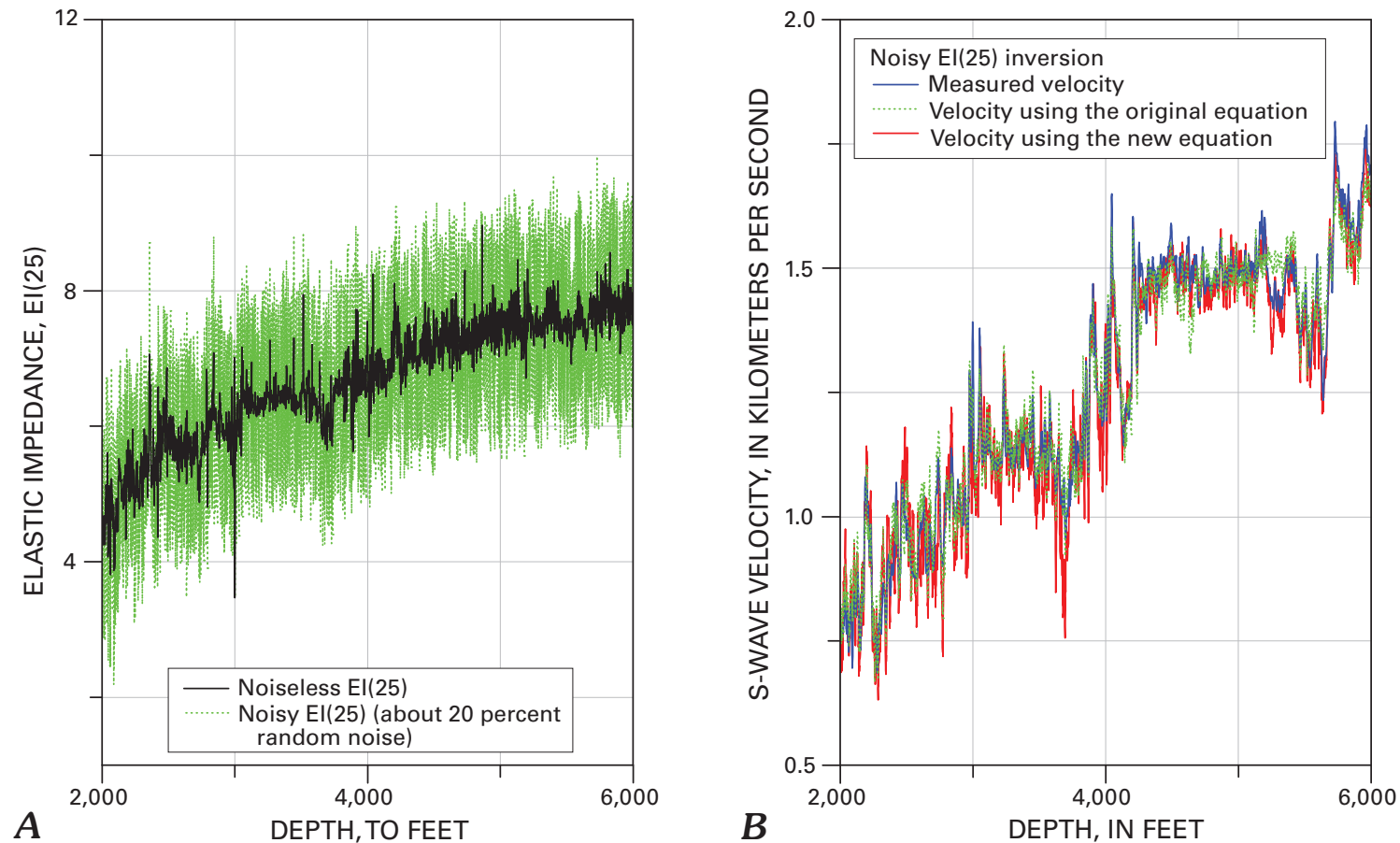

Alpine-1 well

Figure 4. Inversion results using noisy elastic impedance (EI) calculated at an incidence angle of $25^{\circ}$ at the Alpine-1 well. $A$, Noiseless EI(25) with a black line and noisy EI(25) with a green line, $B$, Inversion results using the original and new formulas.

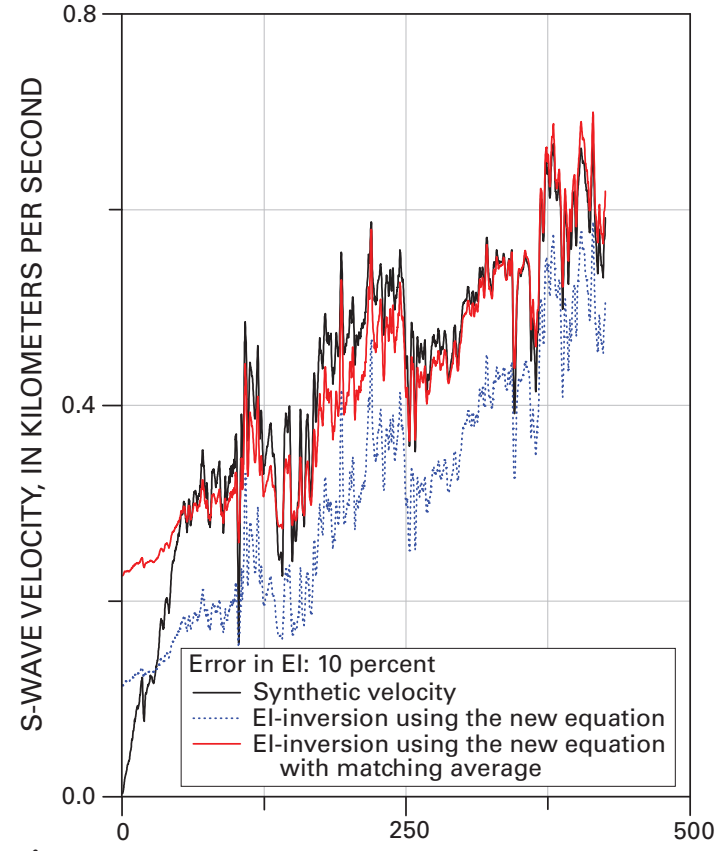

A SUBBOTTOM DEPTH, IN METERS

Keathley Canyon 151-2 well

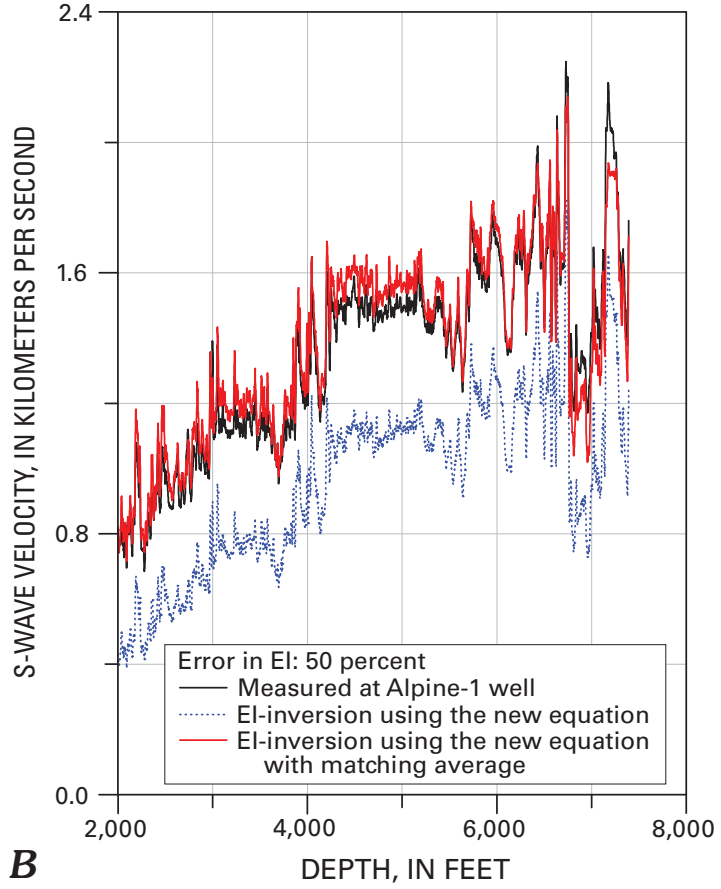

Alpine-1 well

Figure 5. Inversion results from the new formula using noisy elastic impedance (EI). $A$, Inversion results at the Keathley Canyon 151-2 well in the case that the fractional error in El is 10 percent. $B$, Inversion results at the Alpine-1 well in the case that the fractional error in El is 50 percent. 
variations of inverted S-wave velocities are similar to those of the measured S-wave velocities. Therefore, a correction term can be estimated by assuming that an average of inverted $\mathrm{S}$-wave velocities is the same as an average of low-frequency part of S-wave velocities. The red lines in figure 5 are inverted $\mathrm{S}$-wave velocities determined by matching the average $\mathrm{S}$-wave velocities.

\section{Comparison Between Original Inversion and New Inversion Equations}

The original inversion formulation, equation 2 , works well when $\mathrm{S}$-wave velocity is greater than about $0.6 \mathrm{~km} / \mathrm{s}$ or $k$ is greater than about 0.1 . However, the performance deteriorates when $\mathrm{S}$-wave velocity is less than about $0.6 \mathrm{~km} / \mathrm{s}$.

As shown in figure $1 A$, the fractional error in the $\mathrm{S}$-wave velocity due to a large error in $k$ is large when $V_{S}$ is less than about $0.6 \mathrm{~km} / \mathrm{s}$, whereas the error associated with a large error in $k^{*}$ is much smaller when $\beta$ is small. The smallest $k^{*}$ used in the inversion for figure $1 A$ is 0.1 , whereas the smallest $k$ used is 0.01 . Equations 2 and 11 indicate that the $\mathrm{S}$-wave velocity is inversely proportional to $k$ or $k^{*}$. Therefore, unless exact input and $k$ are available, the fractional error in $V_{S}$ increases as $k$ and $k^{*}$ become smaller. The inversion method of the new formulation is stable because $k^{*}$ is greater than 0.1 .

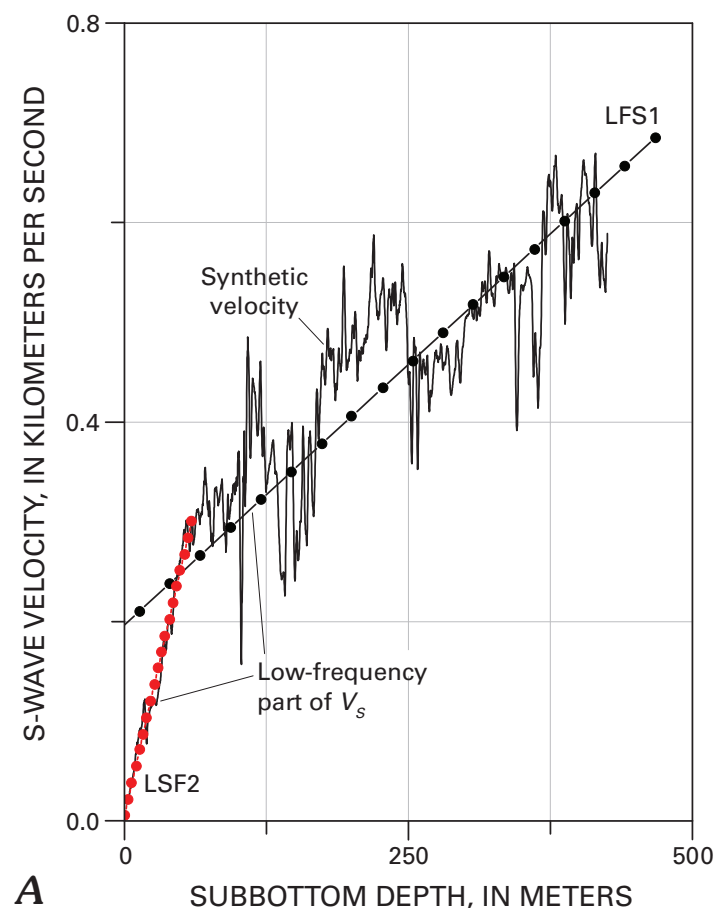

Figures 2 and 3 indicate that both inversion formulations fail to estimate $S$-wave velocities less than about $0.25 \mathrm{~km} / \mathrm{s}$. The $\mathrm{P}$-wave velocity of water-saturated sediments is generally greater than $1.5 \mathrm{~km} / \mathrm{s}$. If it is assumed that the P-wave velocity is about $1.5 \mathrm{~km} / \mathrm{s}$ for sediments whose S-wave velocities are less than $0.25 \mathrm{~km} / \mathrm{s}$, then the $k$ value is less than about 0.03 . For small values of $k$, a small error in $k$ corresponds to a large fractional error in $k$. When $V_{S}$ is less than about $0.2 \mathrm{~km} / \mathrm{s}$, the predicted $S$-wave velocities are much higher than the measured velocities, yielding a large error in $k$. Therefore, it is not practical to use equation 2 for small S-wave velocities.

The failure of equation 11 for small values of S-wave velocity is partly due to its inaccuracy and partly due to the inaccuracy of the low-frequency part of $V_{S}$. Figure $6 \mathrm{~A}$ shows the input $\mathrm{S}$-wave velocity and low-frequency part of $\mathrm{S}$-wave velocity $\left(V_{S}{ }^{L}\right)$ used in the inversion. Previous results are produced using the $V_{S}^{L}$ shown as LSF1 in figure $6 A$. Inversion results with the $V_{S}{ }^{L}$ using LSF2 for depths up to $40 \mathrm{~m}$ and LSF1 for depths greater than $40 \mathrm{~m}$ are shown in figure $6 B$. Use of the new formula leads to more reliable estimates of S-wave velocities, whereas the original formula fails to estimate low $\mathrm{S}$-wave velocities. Therefore, for low $\mathrm{S}$-wave velocities, accurate $V_{S}{ }^{L}$ improves the accuracy of inversion using the new formula, but not for the original formula.

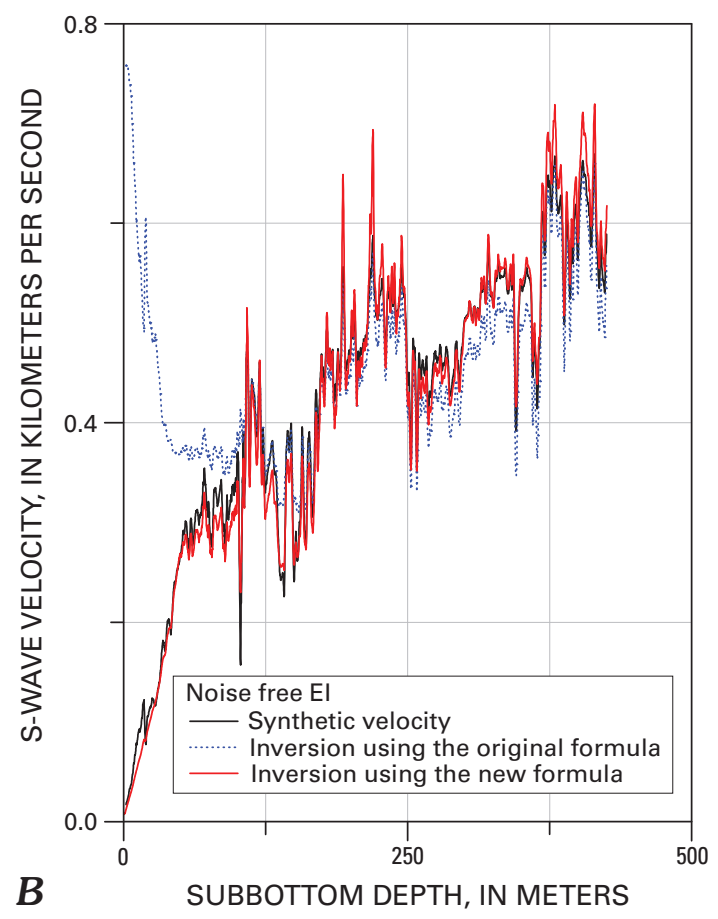

Keathley Canyon 151-2 well

Figure 6. A, The S-wave velocity simulated at the Keathley-Canyon 151-2 well and low-frequency parts of S-wave velocity used in the inversion; previous results are estimated using the least-squares fit (LSF), LSF1, for all depths. $B$, Inversion results using the new low-frequency part of $S$-wave velocities shown in figure $6 A$. The new low-frequency part of S-wave velocity is LSF2 for depths less than 40 meters and is LSF1 for depths greater than 40 meters. 
The effect of $V_{S}^{L}$ on the EI-inversion can be analyzed from the error analysis shown in figure 1 . In the original formulation, only $k$ values control the accuracy of the inversion. As indicated previously, the desired accuracy of $k$ may not be obtained in practice and a small error can be accentuated for low values of $k$. However, in the new formulation, error is dependent upon $\beta$. Therefore, by using an accurate $V_{S}^{L}$, the accuracy of inversion can be increased, even where there are large uncertainties in $k^{*}$.

One problem in using the new equation is that the magnitude of parameter $\beta$ should be small to estimate accurate $S$-wave velocities. In other words, the new equation requires accurate low-frequency part of S-wave velocity. Because of this requirement on $\beta$, the new equation is not optimum for the inversion of GHBS as demonstrated in a later section, "Inversion for Gas Hydrate-Bearing Sediments."

\section{Error in $V_{s}$ Associated with Error in Elastic Impedance}

If there is error only in EI, that is $E I \Rightarrow E I+\Delta E I=$ $E I(1+\Delta E I / E I)=(1+\lambda) E I$, the fractional error in $V_{S}(\varepsilon)$ can be written as

$$
\begin{gathered}
\varepsilon=e^{\frac{-\ln (1+\lambda)}{8 k \sin ^{2} \theta}}-1, \\
\text { and } \varepsilon=e^{\frac{-\ln (1+\lambda)}{8 k^{*} \sin ^{2} \theta}}-1 .
\end{gathered}
$$

Equations $14 \mathrm{a}$ and $14 \mathrm{~b}$ are respective errors that occur when the original and the new equations are used. The $S$-wave velocity for a given error in EI is given by $V_{S}^{*}=V_{S}(1+\varepsilon)$, where $V_{S}^{*}$ and $V_{S}$ are the erroneous and true S-wave velocities, respectively.

Figure 7 shows the gain factor $(G)$, defined as $\mathrm{G}=$ $(1+\varepsilon)$, with respect to fractional errors in EI for various $k$ or $k^{*}$ values. The plot indicates that inverted S-wave velocities are less than the true $\mathrm{S}$-wave velocities when the fractional error in EI is greater than 0.0. The fractional error in $V_{S}$ increases as $k$ or $k^{*}$ decreases. Because $k$ values for the original formulation can be much less than 0.2 , the fractional errors in $V_{S}$ can be large for low S-wave velocities. However, as shown in the model study, the scaling error in EI can be reduced by matching the average $\mathrm{S}$-wave velocities between the low-frequency input and inverted $\mathrm{S}$-wave velocities.

\section{Inversion for Gas Hydrate-Bearing Sediments}

The S-wave velocities for GHBS and host sediments can be very small as demonstrated at the Hydrate Ridge, Offshore Oregon, by Kumar and others (2006). Their S-wave velocities estimated from multicomponent ocean-bottom seismograph data are in the range of 0.15 to $0.35 \mathrm{~km} / \mathrm{s}$. Also, S-wave

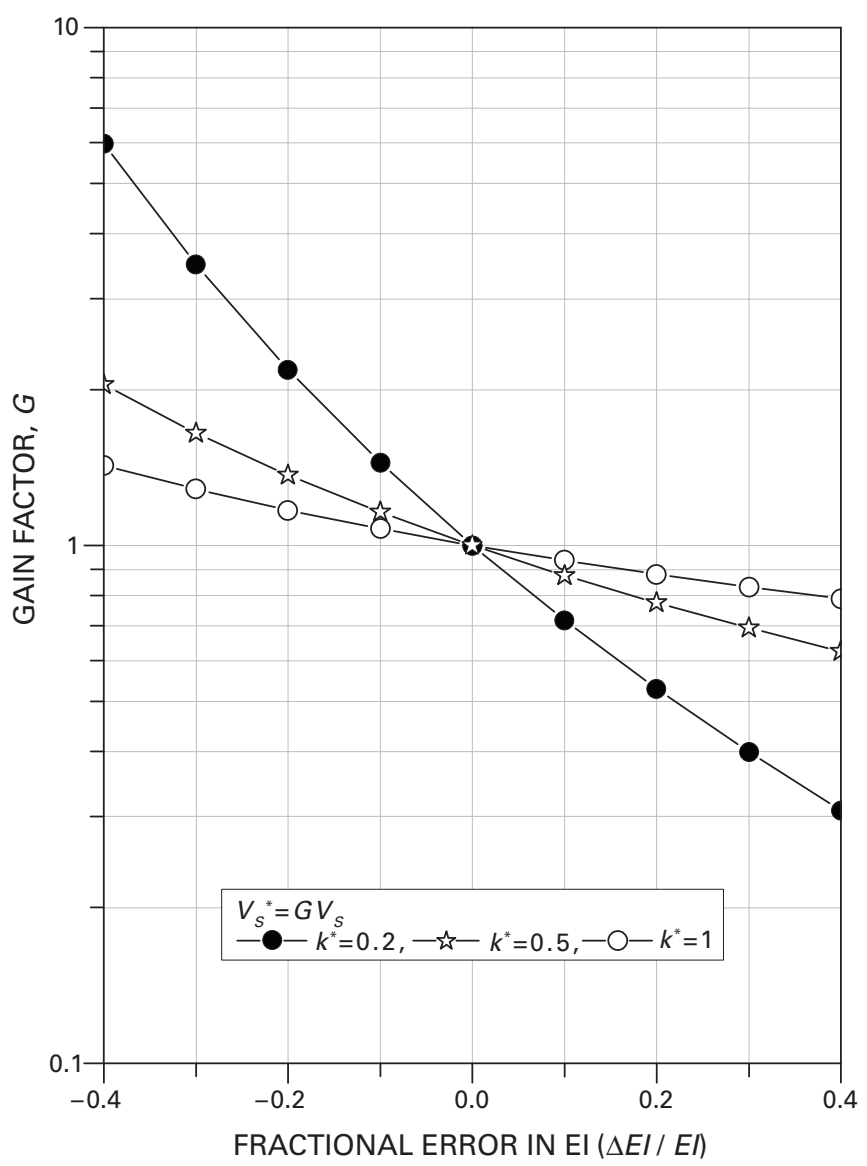

Figure 7. Gain factor $(G)$ with respect to the fractional error in elastic impedance. Fractional error in $V_{s}$ is given by $G-1$.

velocities analyzed from the multicomponent ocean-bottom cable data in the Gulf of Mexico by Hardage and others (2006) are in the range of $0.3 \mathrm{~km} / \mathrm{s}$. The well $\log \mathrm{S}$-wave velocities of GHBS at Hydrate Ridge that were acquired during Ocean Drilling Program Leg 204 vary from $0.25 \mathrm{~km} / \mathrm{s}$ to $0.65 \mathrm{~km} / \mathrm{s}$. However, S-wave velocities of GHBS at the Mallik 5L-38 well site, Mackenzie Delta, Canada, reach $2 \mathrm{~km} / \mathrm{s}$. Therefore, in order to perform EI-inversion for GHBS, all ranges of S-wave velocities should be considered.

To investigate the performance of EI-inversion, synthetic $\mathrm{P}$ - and S-wave velocity logs were generated at the Keathley Canyon 151-2 well, and the data are shown in figure $8 A$. The gas hydrate saturations were calculated from the resistivity log and the velocities were computed using the BGTL with $m=1.5$. The synthetic S-wave velocity varies between $0 \mathrm{~km} / \mathrm{s}$ and 0.9 $\mathrm{km} / \mathrm{s}$.

Figure $8 B$ shows inversion results for GHBS using the same low-frequency part of the S-wave velocity used for figure 6 , which is adequate for water-saturated sediments. The $\mathrm{S}$-wave velocities estimated using the new formula (red line) are much higher for intervals containing moderate amounts of gas hydrate. Conversely, the original equation closely 

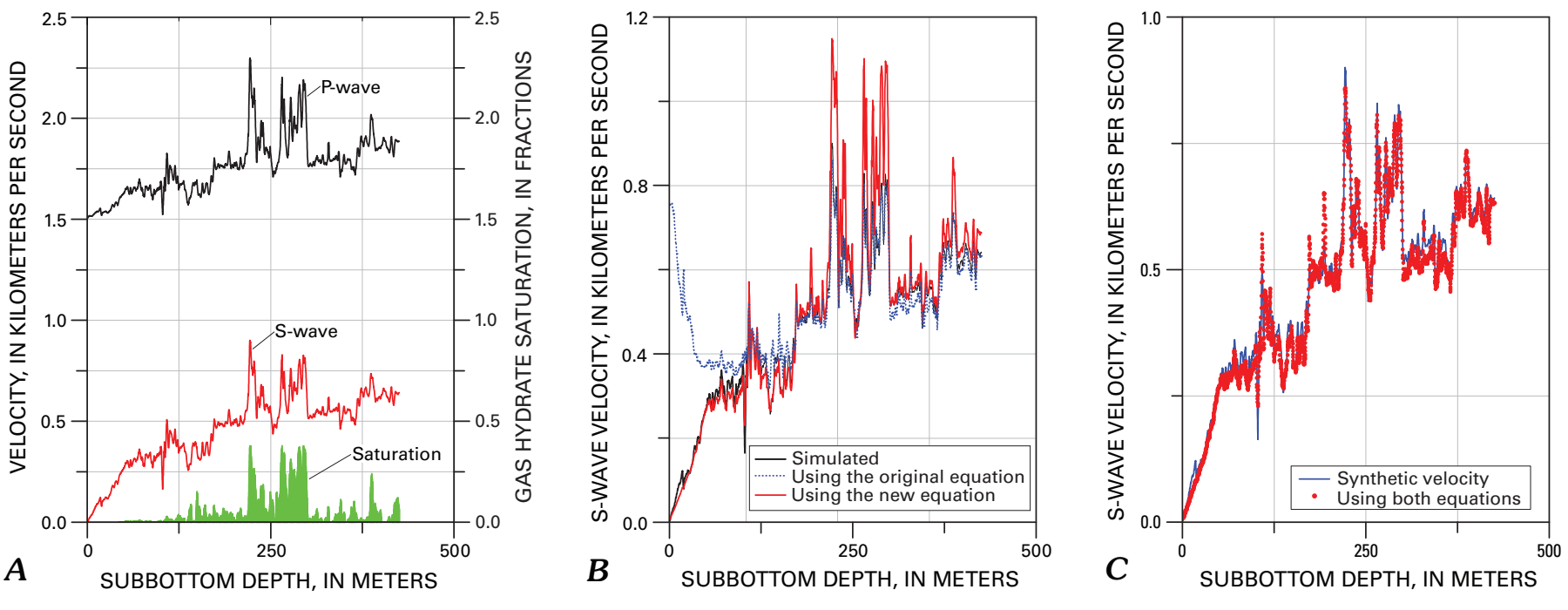

Keathley Canyon 151-2 well

Figure 8. Inversion results for gas hydrate-bearing sediments at the Keathley Canyon 151-2 well. $A$, Synthetic $\mathrm{P}$ - and S-wave velocities predicted from porosity and gas hydrate saturations estimated from the resistivity log using the modified Biot-Gassmann theory by Lee (2002). B, S-wave velocities estimated from the new and original equations. C, S-wave velocities estimated from the proposed inversion method for gas hydrate-bearing sediments.

estimates S-wave velocities for GHBS near $250 \mathrm{~m}$ below sea floor (mbsf) (black dotted line). However, like the previous example, the original equation overestimates the $\mathrm{S}$-wave velocities at shallow depths where velocities are less than about $0.4 \mathrm{~km} / \mathrm{s}$.

The amount of error in $\mathrm{S}$-wave velocities estimated from the new formula can be assessed using the parameter $\beta$. The $V_{S}^{L}$ near $220 \mathrm{mbsf}$ is $0.43 \mathrm{~km} / \mathrm{s}$, whereas $V_{S}$ is about $0.9 \mathrm{~km} / \mathrm{s}$. Therefore, $\beta$ near $220 \mathrm{mbsf}$ is 1.0 . Because the new equation 11 is accurate for small $\beta$, the estimated $\mathrm{S}$-wave velocity near $220 \mathrm{mbsf}$ is inaccurate. Gas hydrate in the pore spaces increases $\mathrm{P}$ - and $\mathrm{S}$-wave velocities significantly for moderate to high gas saturations, so $\beta$ for GHBS can be very large unless the gas hydrate effect on velocity is incorporated in the $V_{S}^{L}$.

The results shown in figure 8 indicate a probable optimum approach applicable for the inversion of GHBS at shallow depths. It is proposed that the new formulation be used when $V_{S}^{L}$ is less than $0.4 \mathrm{~km} / \mathrm{s}$ and the original equation be used when $V_{S}{ }_{S}$ is greater than $0.4 \mathrm{~km} / \mathrm{s}$. The blue line in figure $8 C$ shows $\mathrm{S}$-wave velocities estimated from the proposed method by combining the two equations. Almost the same results are obtained if the new equation is used when $k$ is less than 0.07 and the original equation is used when $k$ is greater than 0.07. Using $k$ is preferable to using $V_{S}{ }^{L}$ to determine when to use the new equation or the original equation because $k$ is estimated from the input data.

It is emphasized that the largest $k$ values appropriate for GHBS are limited by the unconsolidated nature of GHBS (Lee and Collett, 2001). Because they are unconsolidated even at high gas hydrate saturations (Lee and Collett, 2001), the values of $k$ for GHBS rarely exceed 0.25 (that is $V_{S} / V_{P}$ ratio of 0.5 ). When predicting $\mathrm{S}$-wave velocity from $\mathrm{P}$-wave velocity, it is generally assumed that the pore space is filled by water not by gas hydrate. Therefore, the predicted S-wave velocities for highly saturated GHBS are much higher than the actual velocity and yield higher $k$ values for the inversion.

Figure $9 A$ shows the measured $\mathrm{P}$ - and S-wave velocities at the Mallik 5L-38 well and the calculated gas hydrate saturations from the nuclear magneto resonance porosity. As indicated, gas hydrate saturations in some intervals reach about $80-90$ percent. Figure $9 B$ shows the inverted S-wave velocities with $k$ calculated from the predicted S-wave velocity assuming 100-percent water saturation. The estimated $\mathrm{S}$-wave velocities for intervals with high measured S-wave velocities (or high gas hydrate saturation) are highly underestimated because higher values of $k$ than actual $k$ were used in the inversion. Therefore, it is erroneous to use predicted S-wave velocity for the inversion for highly saturated GHBS unless the effects of gas hydrate in the S-wave velocities are accounted for.

On the basis of an analysis by Lee and Collett (2001), the actual $k$ appropriate for highly saturated GHBS is about 0.22 . Figure $9 C$ shows the inversion result by setting $k=0.22$, if the calculated $k$ values are larger than 0.22 . The $S$-wave velocities shown in figure $9 C$ indicate that EI-inversion by limiting the maximum value of $k$ to $k=0.22$ produces accurate $S$-wave velocities at the Mallik 5L-38 well. 


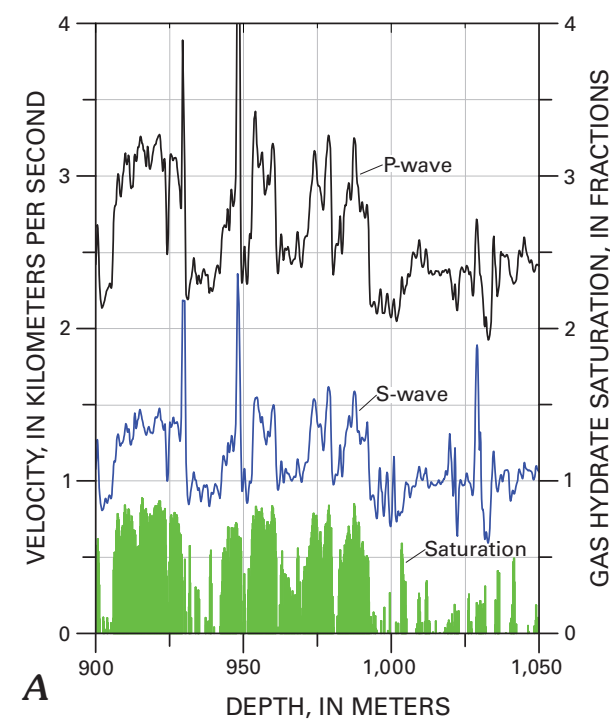

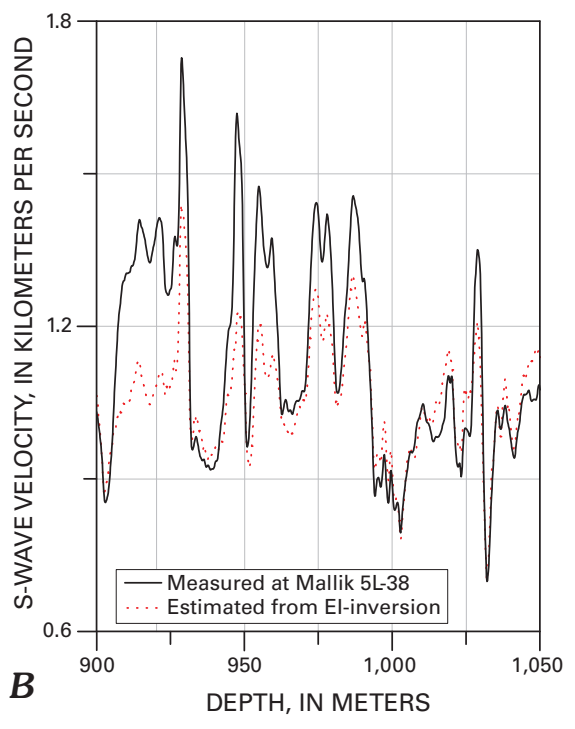

Mallik 5L-38 well

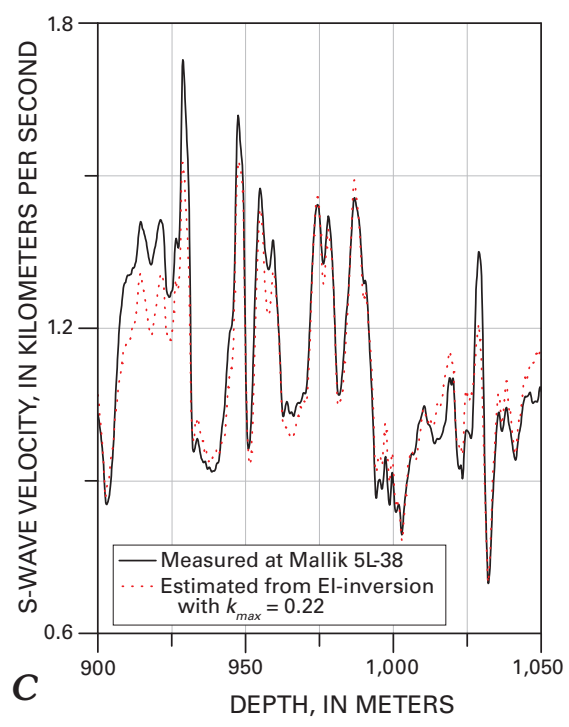

DEPTH, IN METERS

Figure 9. Inversion results for gas hydrate-bearing sediments at the Mallik $5 \mathrm{~L}-38$ well, Canada. $A$, Measured $\mathrm{P}$ - and $\mathrm{S}$-wave velocities and gas hydrate saturations estimated from the nuclear magneto resonance porosity. $B$, Inversion results using the original equation without limiting the calculated $k$ values. $C$, Inversion results using the original equation with limiting the calculated $k$ values to 0.22 , which means that the largest $k$ value used in the inversion is 0.22 .

\section{Conclusions}

Inversion of elastic impedance is problematic when $\mathrm{S}$-wave velocities are smaller than about $0.6 \mathrm{~km} / \mathrm{s}$. The original inversion formulation requires an accurate estimate of the parameter $k$. It is not practical, however, to obtain the accuracy required for the inversion when S-wave velocities are less than about $0.6 \mathrm{~km} / \mathrm{s}$. In order to mitigate this problem, the S-wave velocities are decomposed into the low-frequency (input) and high-frequency (inversion result) parts with appropriate lowand high-frequency parts of elastic impedances. Using lowand high-frequency parts, a new inversion formula is derived with a new parameter $k^{*}$. This new inversion formula is an approximate solution of the original inversion formula, and $k^{*}$ can be large, ranging from 0.1 to 1.0 depending on the $S$-wave velocity. For S-wave velocities less than about $0.6 \mathrm{~km} / \mathrm{s}$, the new equation appears to be appropriate.

This new inversion formula was applied to well logs acquired in the Gulf of Mexico and the North Slope of Alaska. Inversion results indicate that this new formula yields accurate $\mathrm{S}$-wave velocities. When $\mathrm{S}$-wave velocities are greater than about $0.6 \mathrm{~km} / \mathrm{s}$, both inversion methods yield accurate $\mathrm{S}$-wave velocities. However, on the basis of model results, it is observed that the effect of noise in EI is less affected on the results from the new formula when S-wave velocities are less than about $0.6 \mathrm{~km} / \mathrm{s}$.

The accuracy of the new inversion equation can be increased by using an accurate low-frequency part of the $\mathrm{S}$-wave velocity, even in the case that there are large uncertainties in $k^{*}$.
For low S-wave velocities less than about $0.2 \mathrm{~km} / \mathrm{s}$, an accurate $V_{S}^{L}$ enables the new formula to estimate accurate $\mathrm{S}$-wave velocity, whereas it fails to enable the original formula to increase the inversion accuracy. However, the new equation requires a rather accurate low-frequency part of the $\mathrm{S}$-wave velocity. Because of this restriction on the low-frequency part of S-wave velocity, the new equation is not adequate for inversion for GHBS with moderate or high gas hydrate saturations. For inversion of GHBS, using the original equation when $k$ is greater than 0.07 and using the new equation when $k$ is less than 0.07 appears to be appropriate. However, because GHBS is unconsolidated, the permissible largest $k$ value is about 0.22 .

\section{References}

Collett, T.S., 2002, Energy resources potential of natural gas hydrates: American Association of Petroleum Geologists Bulletin, v. 86, p. 1971-1992.

Connolly, Patrick, 1999, Elastic impedance: The Leading Edge, v. 18, p. 438-452.

Hardage, B.A., Muray, Paul, Sava, Diana, Backus, M.M., and Graebner, Robert, 2006, Evaluation of deepwater gas hydrate systems: The Leading Edge, v. 25, p. 572-576.

Jin, Y.K., Lee, M.W., Kim, Y., Nam, S.H., and Kim, K.J., 2003, Gas hydrate volume estimations on the south Shetland continental margin, Antarctic Peninsula: Antarctic Science, v. 15, p. $271-282$. 
Kumar Dhananjay, Sen, M.K., and Bang, N.L., 2006, Seismic characteristics of gas hydrates at Hydrate Ridge, offshore Oregon: The Leading Edge, v. 25, p. 610-612, 614.

Lee, M.W., 2002, Modified Biot-Gassmann theory for calculating elastic velocities for unconsolidated and consolidated sediments: Marine Geophysical Researches, v. 23, p. 403-412.

Lee, M.W., 2006, Inversion of elastic impedances for unconsolidated sediments: U.S. Geological Survey Scientific Investigations Report 2006-5081, 14 p.

Lee, M.W., and Collett, T.S., 2001, Elastic properties of gas hydrate-bearing sediments: Geophysics, v. 66, p. 763-771.

Lu, Shaoming, and McMechan, G.A., 2002, Estimation of gas hydrate and free gas saturation, concentration, and distribution from seismic data: Geophysics, v. 67, p. 582-593.

Lu, Shaoming, and McMechan, G.A., 2004, Elastic impedance inversion of multichannel seismic data from unconsolidated sediments containing gas hydrate and free gas: Geophysics, v. 69 , p. $164-179$.

Mallick, Subhashis, 1999, Some practical aspects on implementation of pre-stack waveform inversion using a genetic algorithm-An example from east Texas Woodbine gas sand: Geophysics, v. 64, p. 326-336.
Mallick, Subhashis, 2001, AVO and elastic impedance: The Leading Edge, v. 20, p. 1094-1104.

Mallick, Subhashis, Huang, X., Lauve, J., and Ahmad, R., 2000, Hybrid seismic inversion-A reconnaissance tool for deepwater exploration: The Leading Edge, v. 19, p. 1230-1251.

Sakai, A., 1999, Velocity analysis of vertical seismic profile (VSP) survey at JAPEX/NOC/GSC Mallik 2L-38 gas hydrate research well, and related problems for estimating gas hydrate concentration, in Dallimore, S.R., Uchida, T., and Collett, T.S., eds., Scientific results from JAPEX/JNOC/ GSC Mallik 2L-38 Gas Hydrate Research Well, Mackenzie Delta, Northwest Territories, Canada: Geological Survey of Canada Bulletin 544, p. 323-340.

Tinivella, Umberta, and Lodolo, Emanuele, 2000, The Blake Ridge bottom-simulating reflector transect-Tomographic velocity field and theoretical model to estimate methane hydrate quantities, in Paull, C.K., Matsumoto, R., Wallace, P.J., and Dillon, W.P., eds., Proceedings of the Ocean Drilling Program, Scientific Results, v. 164: College Station, Texas A\&M University, p. 273-281.

Whitcombe, D.N., 2002, Elastic impedance normalization: Geophysics, v. 67, p. 60-62. 